\title{
HOLMIUM LASER TREATMENT OF AN OBSTRUCTIVE URETEROCELE IN AN ADULT PATIENT: A CASE REPORT AND VIDEO
}

Omer Abdalla ${ }^{1,2,3}$, Yih Chyn Phan ${ }^{3}$, Seshadri Sriprasad ${ }^{1,2}$

${ }^{1}$ Dartford and Gravesham NHS Foundation Trust

${ }^{2}$ Canterbury Christ Church University

${ }^{3}$ Portsmouth Hospitals NHS Trust

Corresponding author omer.abdalla@doctors.org.uk

Submitted: December 12, 2018. Accepted: January 8, 2019. Published: February 21, 2019.

\begin{abstract}
Ureteroceles are uncommon in adults and frequently found incidentally in the majority of cases. Surgical treatment is indicated in patients with bothersome symptoms or complications. Several deroofing techniques have been described in the literature including nephroscopic scissor, Collin's knife, and laser. The use of lasers became popular over the last 2 decades. Herein we report a case and demonstrate our technique of using a holmium laser to treat an adult patient with symptomatic obstructive unilateral ureterocele.
\end{abstract}

An ureterocele is a cystic dilatation of distal intramural ureter commonly found in the pediatric population (Figure 1); however, it can be an incidental finding in the adult population. Albeit rare, patients with bothersome symptoms or complicated ureteroceles should be offered appropriate treatment. We hereby report a case and video of using a holmium laser to treat an adult who was found to have an obstructed ureterocele.

\section{CASE REPORT}

A 39-year-old woman presented to the department with a few months' history of left loin pain. She had an ultrasound scan which showed a left ureterocele. Initially, she was managed conservatively but she represented again with ongoing pain. She was otherwise fit and well and her examination revealed soft nontender abdomen. Her kidney functions were normal.

She had a CT (computed tomography) urogram which showed a left hydroureter and a typical cobra head appearance of her left ureterocele (Figures 2 and 3).
Her mercaptoacetyltriglycine (MAG3) scan showed a delayed drainage of her left renal system, suggesting that she had an obstructed left ureterocele. She subsequently underwent a transurethral holmium laser incision of her left ureterocele and a left ureteric stent insertion (Figure 4). The stent was removed 6 weeks later, and she made an uneventful recovery with no further pain or symptoms. She was asymptomatic at 3- and 9- months follow-up, and her follow-up CT urogram scan was normal with no evidence of hydroureter (Figure 5).

\section{TECHNIQUE}

A 22 Fr rigid cystoscope was inserted into the bladder, and then a Terumo guidewire was passed into left ureterocele up to left renal pelvis. A 360-micron holmium laser fibre was used and passed over a ureteric catheter for better stability to incise the anterior surface of the left ureterocele using an $8 \mathrm{~Hz}$ and $0.8 \mathrm{~J}$ energy setting. Incision was performed until the ureterocele was wide open (Video 1), and then a 6 Fr ureteric stent was placed. 
FIG 1. Graphic representation of a typical ureterocele.

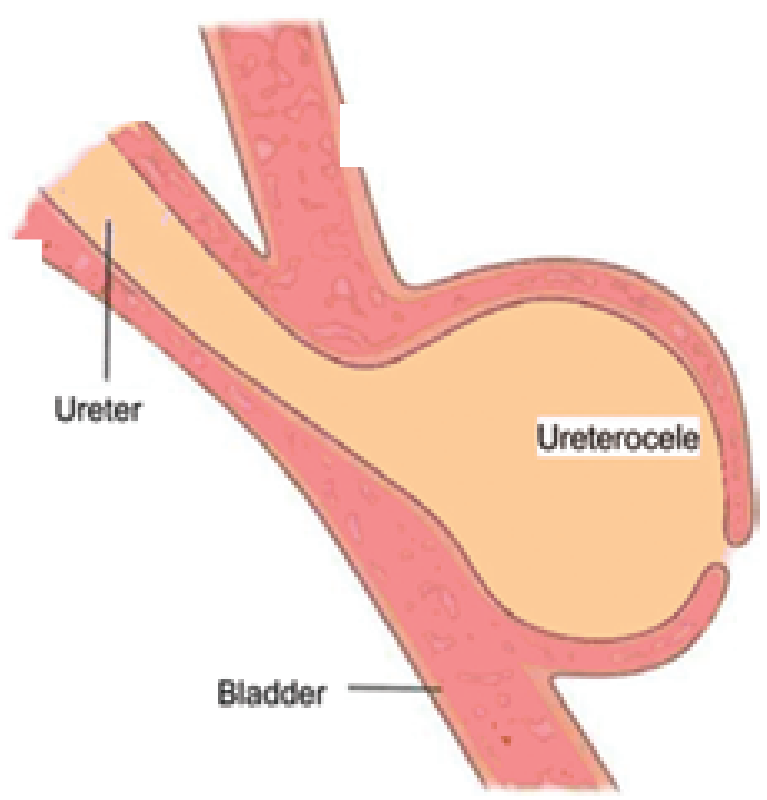

FIG 2. Computed tomography demonstrating a typical cobra head appearance of a left ureterocele.

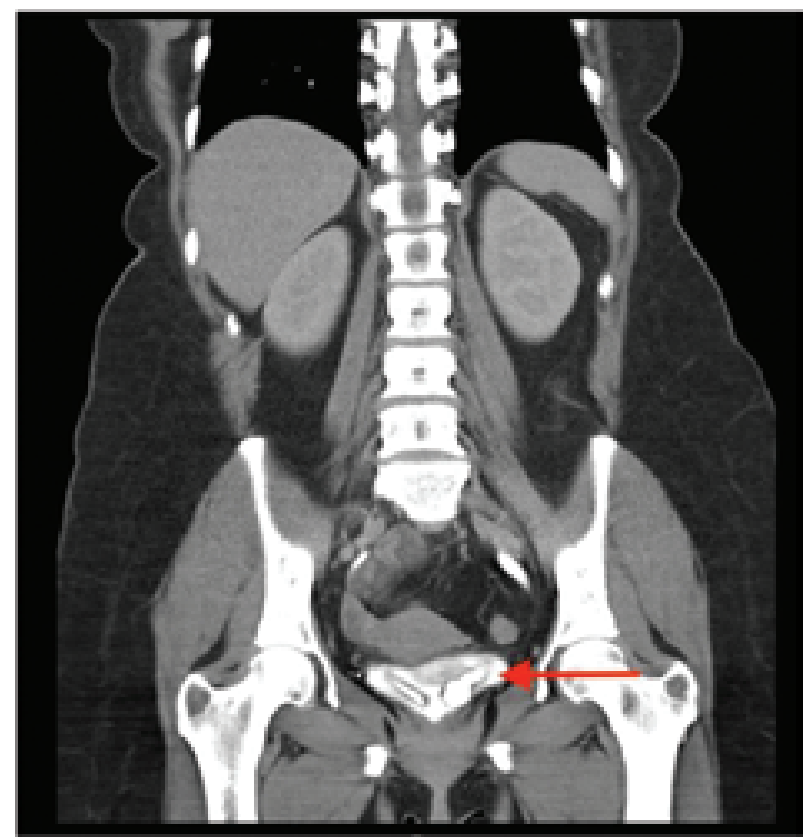

FIG 3. Computed tomography demonstrating left hydroureter.

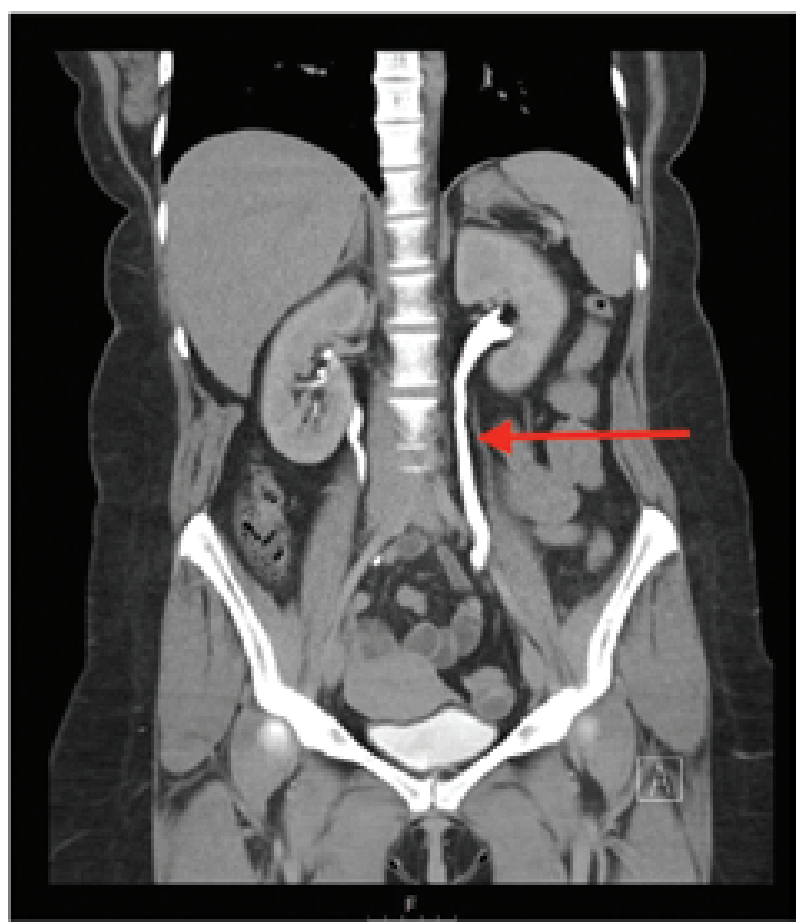

\section{DISCUSSION}

The incidence of ureteroceles has been reported as 1 in 500 with a $4: 1$ preponderance in females to males. ${ }^{1,2}$ Ten percent of the ureteroceles are bilateral.

Broadly, they can be classified into intravesical and extravesical or ectopic.

Pediatric ureteroceles are often associated with duplicated collecting systems in ectopic positions while adult ureteroceles are usually found in unilateral single systems in intravesical orthotopic positions. The clinical presentation of ureterocele varies from asymptomatic to recurrent urinary tract infections, lower urinary tract symptoms, or flank pain. In rare cases, urinary retention secondary to large ureterocele has also been reported before, and stones within ureterocele are frequently reported at a rate up to $39 \% .^{3}$ In this case, the patient presented with left loin pain due to likely obstructive ureterocele with no evidence of calculi within the ureter or ureterocele. Classically, a cobra head sign is synonymous with an intravesical ureterocele. ${ }^{4-6}$ 
FIG 4. (A-C) Cystoscopic appearance demonstrating ballooning (filling) of ureterocele and guide wire placed.

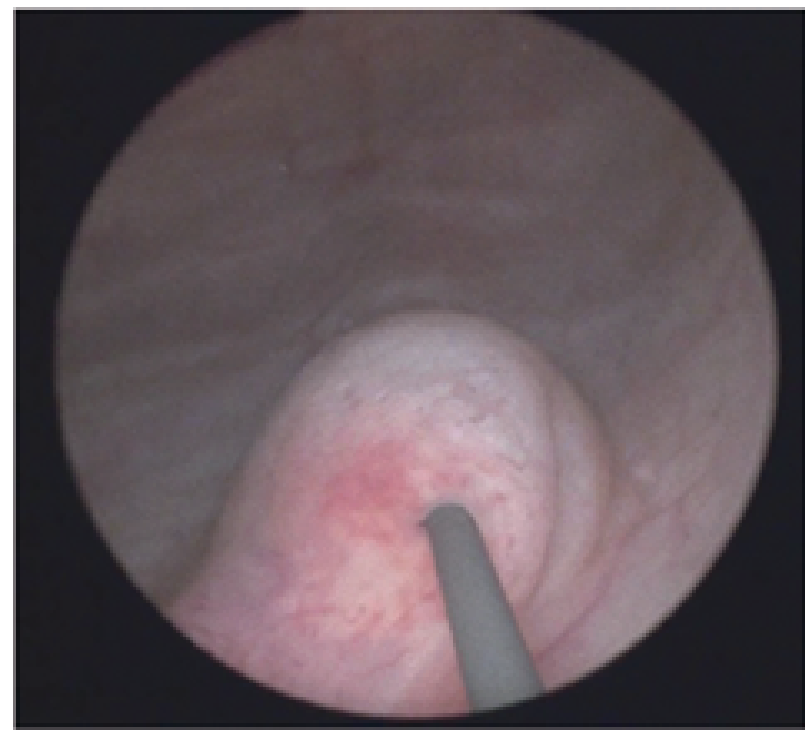

A

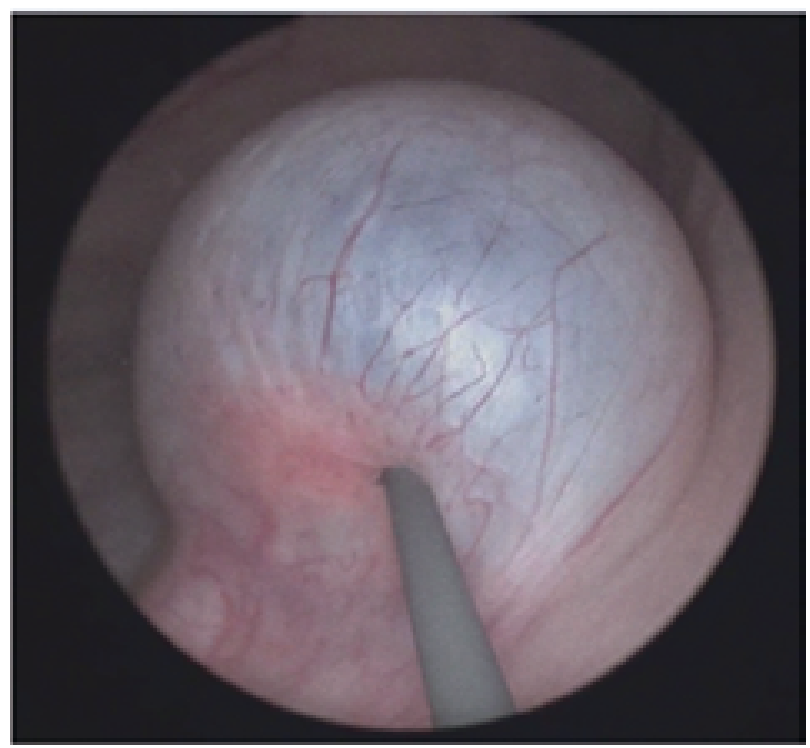

C

Several endoscopic deroofing of ureteroceles tech-niques have been described in the literature including using a nephroscopic scissor, a Collin's knife, a holmium laser and a potassium titanyl phosphate (KTP) laser. Laser energy results in complete tissue destruction, thus reduced the risk of recurrence or stenosis when

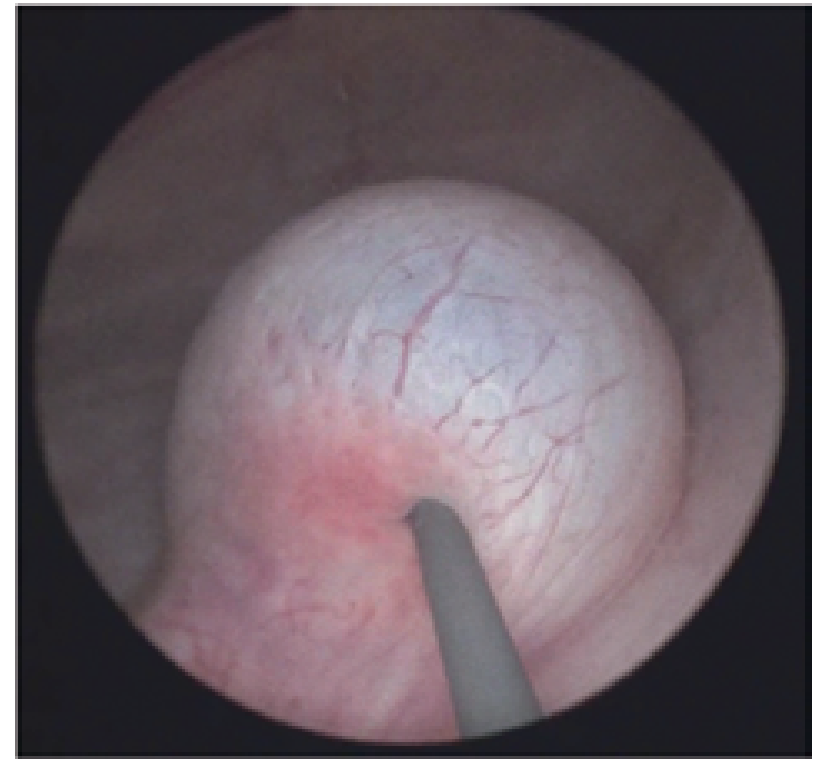

B

compared to standard incision or electrocautery. ${ }^{7}$ Furthermore, laser permits precise incision due to no-thermal effect beyond contact point unlike other modalities. ${ }^{8}$ The use of a KTP laser to treat ureterocele has only been reported by Gholdoian et al. on 9 children, using 200 micron laser fibre and energy settings of 2.5-5 Watts; this resulted in 5 patients requiring no further procedures. ${ }^{9}$ Interestingly, Ninomiya et al. have also reported using a half-loop incision technique to treat symptomatic ureterocele. ${ }^{10}$

Previously, Gupta et al. have reported good outcome on 5 adult patients who have received endoscopic incision of ureteroceles using a Nd-Yag laser. ${ }^{11}$ They advocated that laser could make a precise, bloodless 
FIG 5. Computed tomography urogram showing a complete resolution of the left ureterocele.

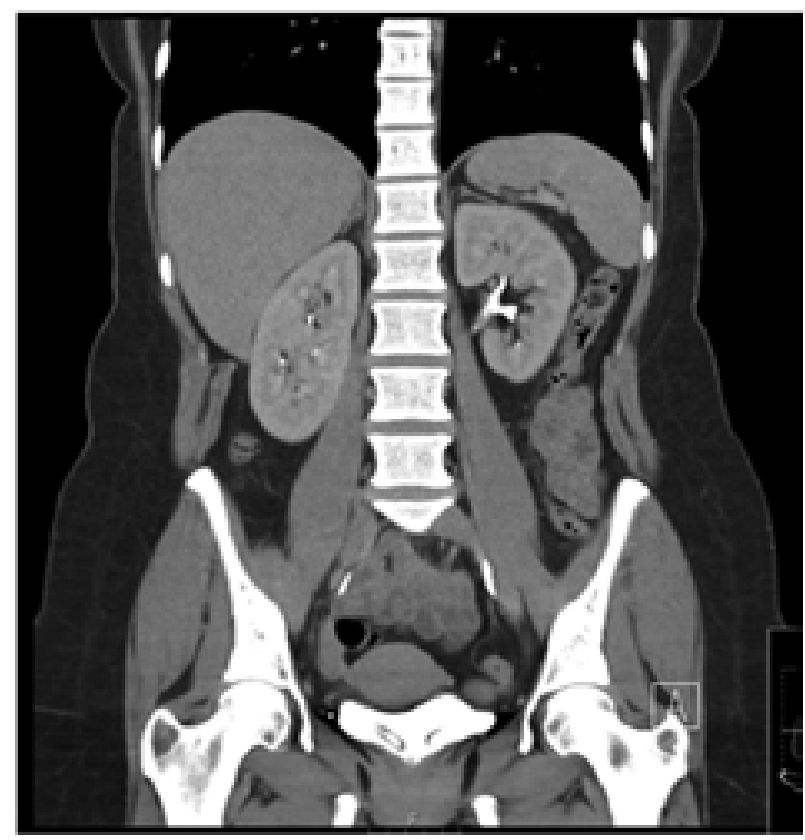

and accurate incision of obstructed ureteroceles. In China, Liu et al. also explored the use of Greenlight (TM) laser to treat 30 adult patients with ureterocele. ${ }^{12}$ Similarly, they have reported positive outcomes using Greenlight (TM) laser. Shah et al. reported the outcome of holmium laser incision and lithotripsy of ureterocele with associated stones in 16 adult patients, this resulted in complete resolution of ureterocele with 3 patients had micturating cystouretherogram (MCU) evidence of reflux at 3 months but this was no longer evident at 6-months follow-up. ${ }^{13}$

Likewise, this case highlights that symptomatic obstructive ureterocele can be effectively treated with a holmium laser. Although no MCU was performed to check vesicoureteric reflux (VUR), the patient's symptoms resolved and she remained asymptomatic up to 9 months follow up. Moreover, CT urogram showed complete resolution of ureterocele and hydroureter.

\section{CONCLUSION}

Holmium laser incision of ureterocele is feasible and effective in the management of symptomatic ureterocele.

\section{REFERENCES}

1. Uson AC, Lattimer JK, Melicow MM. Ureteroceles in infants and children: a report based on 44 cases. Pediatrics 1961; 27: 971-7.

2. Rickwood AMK, Reiner I, Jones M, Pournaras C. Current management of duplex-system ureteroceles: experience with 41 patients. Br J Urol 1992;70:196-200.

3. Rompré-Brodeur A, Andonian S. Adult bilateral ureteroceles presenting with lower urinary tract symptoms and acute urinary retention. Case Rep Urol 2018;2018:3186060

4. Tirman PA, Dyer RB. The cobra head sign. Abdom Imaging 2015 Mar;40(3):609-10.

5. Xiang H, Han J, Ridley WE, Ridley LJ. Cobra head sign: Ureterocele. J Med Imaging Radiat Oncol 2018 Oct;62 Suppl 1:67.

6. Chavhan GB. The cobra head sign. Radiology. 2002 Dec;225(3):781-2.

7. Marr L, Skoog SJ. Laser incision of ureterocele in the pediatric patient. J Urol 2002;167:280-282.

8. Jankowski JT, Palmer JS. Holmium: yttrium-aluminumgarnet laser puncture of ureteroceles in neonatal period. Urology 2006;68:179-81.

9. Gholdoian CG, Thayer K, Hald D, Rajpoot D, Shanberg AM. Applications of the KTP laser in the treatment of posterior urethral valves, ureteroceles, and urethral strictures in the pediatric patient. J Clin Laser Med Surg 1998 Feb;16(1):39-43.

10. Ninomiya S, Kawahara T, Mochizuki T, Yao M, Teranishi JI, Uemura H. The half-loop transurethral incision technique for bilateral ureterocele in adult. Urol Case Rep 2018;18:6-8. Published 2018 Mar 21. doi:10.1016/j.eucr.2018.02.017

11. Gupta NP, Ansari MS, Singh I. Laser endoscopic incision: a viable alternative to treat adult ureterocele. Int Urol Nephrol 2001;33(2):325-8.

12. Liu C, Chen W, Xie C, et al. Efficacy and safety of transurethral photoselective Greenlight( $\left.{ }^{\mathrm{TM}}\right)$ laser vaporization for the treatment of orthotopic ureteroceles in adults. Photomed Laser Surg 2015;33(6):326-29.

13. Shah HN, Sodha H, Khandkar AA, et al. Endoscopic management of adult orthotopic ureterocele and associated calculi with holmium laser: experience with 16 patients over 4 years and review of literature. J Endourol 2008;3:489-96. 